\title{
Dynamics of pneumococcal colonization in healthy Dutch children
}

Correspondence
D. Bogaert
d.bogaert@erasmusmc.nl

Received 1 August 2005

Revised 27 October 2005

Accepted 7 November 2005
D. Bogaert, ${ }^{1}$ M. Sluijter, ${ }^{1}$ N. Lemmens-den Toom, ${ }^{2}$ T. J. Mitchell, ${ }^{3}$ W. H. F. Goessens, ${ }^{2}$ S. C. Clarke, ${ }^{4}$ R. de Groot ${ }^{5}$ and P. W. M. Hermans ${ }^{5}$

\author{
'Department of Pediatrics, Erasmus MC-Sophia, Room Ee 1500, Dr Molewaterplein 50, \\ 3015 GE Rotterdam, The Netherlands \\ ${ }^{2}$ Department of Medical Microbiology and Infectious Diseases, Erasmus MC, Rotterdam, \\ The Netherlands \\ ${ }^{3}$ Division of Infection and Immunity, Institute of Biomedical and Life Sciences, University of \\ Glasgow, Glasgow, UK \\ ${ }^{4}$ Scottish Meningococcus and Pneumococcus Reference Laboratory, Stobhill Hospital, Glasgow, \\ UK \\ ${ }^{5}$ Department of Pediatrics, Radboud University, Nijmegen Medical Centre, Nijmegen, \\ The Netherlands
}

A recent study of pneumococcal colonization in 3198 healthy children of 1-19 years of age in The Netherlands showed pneumococcal colonization in $19 \%$ of the children, with a peak incidence of $55 \%$ at the age of 2 years; an age-related serotype distribution was also found. In the present study, the genetic background and resistance profiles of 578 pneumococcal isolates from the latter study were characterized by means of chromosomal genotyping and susceptibility testing. In contrast to the age-related serotype distribution observed previously, the genetic background of the strains was not age related. Few strains were found showing close homology ( $>95 \%)$ with the international clones Spain ${ }^{9 \mathrm{~V}}$-3 (ten isolates showed homology), England ${ }^{14}-9$ (four isolates), Tennessee ${ }^{23 F}-4$ (two isolates), $\mathrm{CSR}^{14}-10$ (one isolate) and Sweden ${ }^{15 \mathrm{~A}}-25$ (one isolate). In total, $19 \%$ of strains showed resistance to one or more antibiotics. Resistance to cotrimoxazole, tetracycline, erythromycin and penicillin was found in $12 \cdot 9,5 \cdot 6,5 \cdot 0$ and $2 \cdot 7 \%$ of isolates, respectively. Multidrug resistance was found in $1.9 \%$ of strains. In conclusion, pneumococcal colonization isolates from healthy Dutch children represent a heterogeneous, mostly antibiotic susceptible, genetic population.

\section{INTRODUCTION}

Streptococcus pneumoniae is one of the major pathogens causing invasive disease and respiratory tract infections worldwide. Risk groups for pneumococcal infections are young children, the elderly, and immunodeficient patients. Despite adequate antibiotic treatment, morbidity and mortality due to pneumococcal disease remain high (Butler et al., 1999). In addition, the increasing (multi)drug resistance among pneumococcal isolates hampers adequate treatment (Centers for Disease Control and Prevention, 1997; Crook \& Spratt, 1998; Klugman, 1996; Tomasz, 1997).

Nasopharyngeal colonization with pneumococci is common; in general, humans are colonized at least once early in life. Although colonization with pneumococci is mostly

Abbreviations: MLST, multilocus sequence typing; PMEN, Pneumococcal Molecular Epidemiological Network; RFEL, restriction fragment end-labelling; ST, sequence type. asymptomatic, it can progress to respiratory or even systemic disease as a result of a (temporary) defect in the mucosal barrier function, e.g. as a result of a viral infection. Importantly, pneumococcal disease has to be preceded by nasopharyngeal colonization with the homologous strain (Faden et al., 1990; Gray et al., 1980). Moreover, pneumococcal colonization causes horizontal spread of this pathogen within the community; for example, crowding, which occurs in hospitals, day-care centres and jails, enhances horizontal spread of pneumococcal strains (Hoge et al., 1994; Kristinsson, 1995; Mandigers et al., 1994; Muñoz et al., 1991; Principi et al., 1999). Because the highest incidence of pneumococcal colonization, and the highest crowding index, are found in young children, this risk group is considered to be the most important vector for horizontal dissemination of pneumococcal strains within the community (Leiberman et al., 1999). New pneumococcal conjugate vaccines are highly effective against invasive disease in young children (Black et al., 2002). Furthermore, a protective effect 
against mucosal infections, such as (recurrent) otitis media, albeit limited, has been observed (Black et al., 2002; Eskola et al., 2001). At nasopharyngeal level, however, replacement of vaccine-type pneumococci with non-vaccine serotypes, as a result of vaccination, has also been observed (Dagan et al., 2002; Mbelle et al., 1999; Veenhoven et al., 2003). In addition, replacement of mucosal disease, i.e. (recurrent) acute otitis media, has been found (Eskola et al., 2001; Veenhoven et al., 2003). What effect this serotype replacement has on invasive disease remains unclear, although it has been demonstrated that several non-vaccine serotypes clearly have high potential for causing invasive disease (Brueggemann et al., 2003). Because few data are available on the agerelated incidence and serotype distribution of S. pneumoniae among healthy children, a cross-sectional study was performed in the summer of 2002 among 3200 healthy children aged 1-19 years, in which the prevalence and determinants of pneumococcal carriage were studied (Bogaert et al., 2003). That study showed a significant age-related colonization rate, with a peak incidence of $55 \%$ at 3 years of age, followed by a gradual decline to a stable colonization rate of $10 \%$, which was reached after the age of 10 years. Moreover, a significant age-related serotype distribution was noticed, with a primary peak of 7 -valent conjugate vaccine $(7 \mathrm{vPCV})$ serotypes early in life, followed by a secondary peak with non-vaccine serotypes (Bogaert et al., 2003).

In this study, we investigated the molecular epidemiological dynamics and resistance profiles of the pneumococcal strains collected during the latter study in order to obtain detailed insight into the occurrence and age-related distribution of pneumococcal genotypes and resistance profiles.

\section{METHODS}

Bacterial isolates. In total, 3198 healthy children, aged 1-19 years, who were participating in a national meningococcal vaccination campaign in Rotterdam, were enrolled. All children were residents of Rotterdam, and were vaccinated either in July (age 12 months to 5 years, and 15-19 years) or September (age 6-15 years) of the year 2002. Signed informed consent was obtained from the parent accompanying the participating children under the age of 16 , and directly from the children above the age of 16. Demographic data were collected as described previously (Bogaert et al., 2003). The study was approved by the Medical Ethics Review Board of Erasmus MC, Rotterdam, The Netherlands.

Cultures. Nasopharyngeal samples were obtained with rayon-tipped dacron pernasal swabs (Copan, Italy), transported in Amies transport medium to the medical microbiology laboratory, and plated within $6 \mathrm{~h}$ of sampling. The swabs were plated on gentamicin blood agar for the isolation of S. pneumoniae. Identification of S. pneumoniae isolates was performed by standard methods, as described by Lenette et al. (1985). The pneumococcal isolates were serotyped by the capsular swelling method (Quellung reaction), using commercially available antisera (Statens Serum Institute, Copenhagen, Denmark). Susceptibility testing was performed by the disk-diffusion method. Resistance was defined by measuring the zone diameters for the respective antibiotics, as defined by the National Committee for Clinical Laboratory Standards (NCCLS) (2002). Strains showing reduced susceptibility to oxacillin were additionally tested for penicillin and cefotaxime resistance by the Etest ( $\mathrm{AB}$ Biodisk). Multidrug resistance was defined as resistance to three or more classes of antimicrobial agents.

Restriction fragment end-labelling (RFEL) typing. Pneumococcal strain typing by RFEL was done as described by van Steenbergen et al. (1995), and adapted by Hermans et al. (1995). Briefly, purified pneumococcal DNA was digested by the restriction enzyme EcoRI. The DNA restriction fragments were end-labelled at $72{ }^{\circ} \mathrm{C}$ with $\left[\alpha-{ }^{32} \mathrm{P}\right] \mathrm{dATP}$ using DNA polymerase (Goldstar; Eurogentec). After the radiolabelled fragments were denatured, and separated electrophoretically on a $6 \%$ polyacrylamide sequencing gel containing $8 \mathrm{M}$ urea, the gel was transferred onto filter paper, vacuum dried (HBI), and exposed for variable times at room temperature to ECL hyperfilm (Amersham Laboratories).

Computer-assisted analysis of DNA band patterns. RFEL autoradiographs were converted to images (Agfa Arcus II; Agfa Gevaert), and analysed by computer (Windows version Bionumerics; Applied Maths). DNA fragments were analysed as described previously (Sluijter et al., 1998). For evaluation of the genetic relatedness of the isolates, we used the following definitions: isolates of a particular RFEL type are $100 \%$ identical by RFEL analysis (Centers for Disease Control Prevention, 1997); an RFEL cluster represents a group of RFEL types that differ in only one band (approx. $>95 \%$ genetic relatedness) (Black et al., 2002).

Table 1. Serotype distribution of the pneumococcal isolates

\begin{tabular}{|lc|}
\hline Type & Total number of pneumococci $(\%)$ \\
\hline S. pneumoniae & $601(100 \%)$ \\
7 vPCV types & $250(41 \cdot 6 \%)$ \\
Non-vaccine types & $351(58 \cdot 4 \%)$ \\
7vPCV types & \\
Serotype 6B & $69(11 \cdot 5 \%)$ \\
Serotype 19F & $68(11 \cdot 3 \%)$ \\
Serotype 23F & $53(8 \cdot 8 \%)$ \\
Serotype 14 & $23(3 \cdot 8 \%)$ \\
Serotype 18C & $17(2 \cdot 8 \%)$ \\
Serotype 9V & $14(2 \cdot 3 \%)$ \\
Serotype 4 & $6(1 \cdot 0 \%)$ \\
Non-vaccine types & \\
Serotype 6A & $40(6 \cdot 7 \%)$ \\
Serotype 3 & $36(6 \cdot 0 \%)$ \\
Serotype 11 & $31(5 \cdot 2 \%)$ \\
Serotype 8 & $21(3 \cdot 5 \%)$ \\
Serotype 15 & $19(3 \cdot 2 \%)$ \\
Serotype 19A & $19(3 \cdot 2 \%)$ \\
Serotype 10 & $18(3 \cdot 0 \%)$ \\
Serotype 23A & $16(2 \cdot 5 \%)$ \\
Serotype 16 & $12(2 \cdot 0 \%)$ \\
Serotype 38 & $12(2 \cdot 0 \%)$ \\
Serotype 7 & $10(1 \cdot 7 \%)$ \\
Other serotypes & $93(15 \cdot 4 \%)$ \\
Untypable $\dagger$ & $31(5 \cdot 2 \%)$ \\
\hline
\end{tabular}

*Other serotypes were $1,5,9 \mathrm{~N}, 12,17,18 \mathrm{~A}, 19 \mathrm{~B}, 20,21,22,23 \mathrm{~B}, 24$, $29,31,33,34,35,36,37,42,44$ and 47.

$\dagger$ The 31 untypable strains were Omniserum positive, but unresponsive to the available group or type sera. 

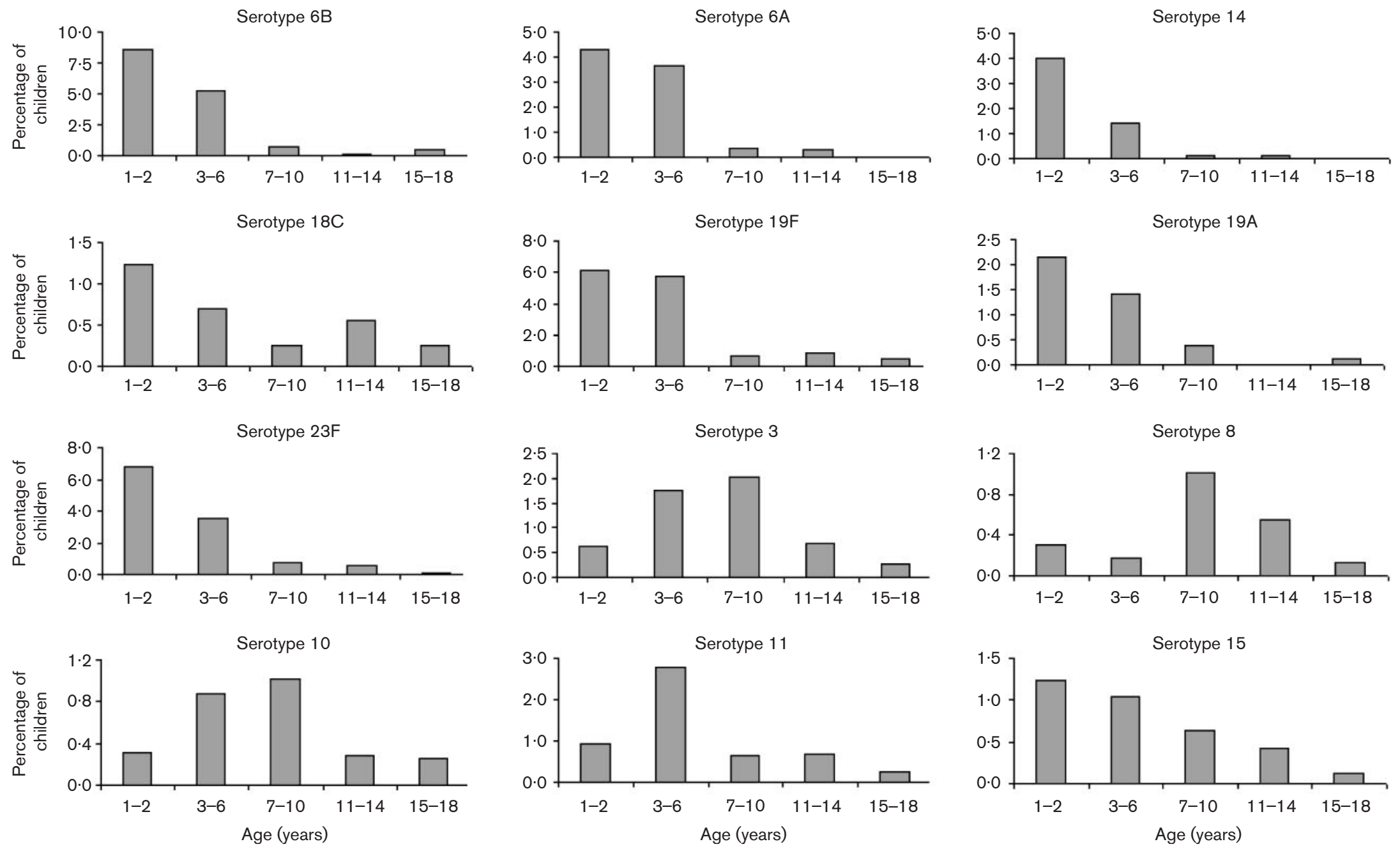

Fig. 1. Age-related serotype-specific prevalence of pneumococcal strains during colonization. The prevalence is depicted as a percentage of the total number of children tested. Data are clustered for the ages 12-36 months, 3-6 years, 7-10 years, 11-14 years and 15-18 years. 


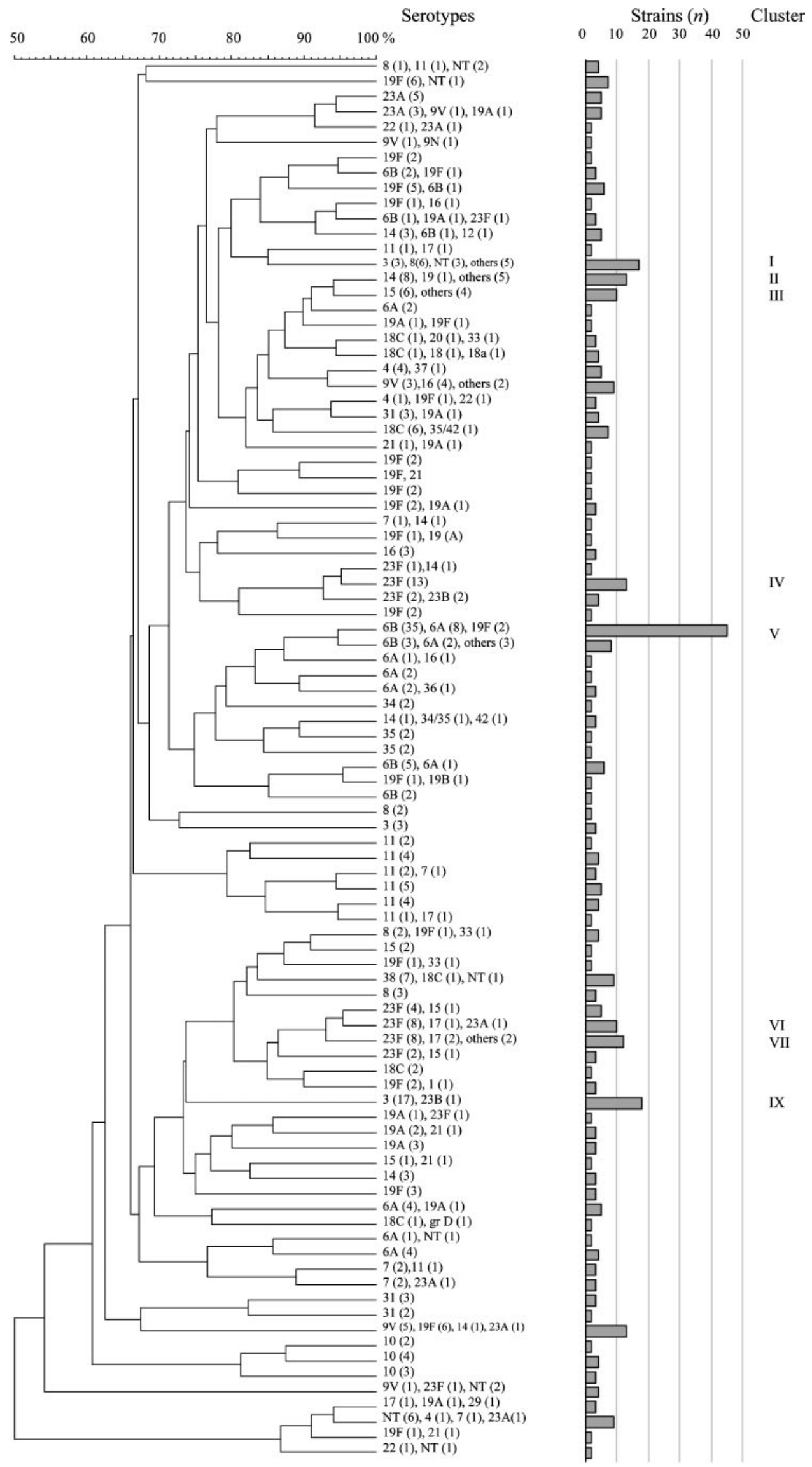


Table 2. Properties of the most predominant genetic clusters

NT, not typable.

\begin{tabular}{|c|c|c|c|c|}
\hline Cluster & $\begin{array}{c}\text { Number of } \\
\text { isolates }\end{array}$ & Serotype & $\begin{array}{l}\text { Number of } \\
\text { genotypes }\end{array}$ & $\begin{array}{c}\text { Mean age } \\
\text { (years) }^{*}\end{array}$ \\
\hline I & 17 & $3(3), 8(6)$, NT $(3)$, others $(6)$ & 3 & 11 \\
\hline II & 13 & $14(8)$, others $(5)$ & 4 & 4 \\
\hline III & 10 & 15 (6), others (4) & 2 & 6 \\
\hline IV & 13 & $23 \mathrm{~F}(13)$ & 4 & 3 \\
\hline $\mathrm{V}$ & 45 & 6B (35), 6A (8), 19F (2) & 5 & 4 \\
\hline VI & 10 & $23 \mathrm{~F}(8)$, others $(2)$ & 3 & 5 \\
\hline VII & 12 & $23 \mathrm{~F}(8), 17(2)$, others $(2)$ & 3 & 4 \\
\hline VIII & 18 & 3 (17), others (1) & 2 & 7 \\
\hline IX & 13 & $9 \mathrm{~V}(5), 19 \mathrm{~F}(6)$, others $(2)$ & 4 & 5 \\
\hline
\end{tabular}

${ }^{\star}$ Mean age of the children carrying the isolates.

International comparison. The genotypes were compared with an international collection of pneumococcal isolates representing 751 distinct RFEL types originating from 17 different countries in America, Europe, Africa and Asia (Bogaert et al., 2002, 2005; Hermans et al., 1997; Overweg et al., 2000), in which the first 26 international pandemic clones, as described by the Pneumococcal Molecular Epidemiological Network (PMEN) in 2002, are present (McGee et al., 2001).

Multilocus sequence typing (MLST). The genotypes of the 24 largest clusters $(n>4)$ were verified by MLST analysis, and one, two or three isolates per cluster were analysed. For this purpose, a fully automated method for MLST was used, as described by Jefferies et al. (2003). The MLST types were compared with the global PMEN database (http://www.pneumo.com/physician/pmen/pmen_history.asp).

Data analysis. $P$ values for differences were calculated with the $\chi^{2}$ test, using GraphPad Prism version 3.00 for Windows (GraphPad Software).

\section{RESULTS}

In total, 601 pneumococci were isolated from 3198 healthy children aged 1-19 years visiting the meningococcal vaccination campaign in the summer of 2002 in the city of Rotterdam, The Netherlands. The most prevalent serotypes were $6 \mathrm{~B}, 19 \mathrm{~F}, 23 \mathrm{~F}, 6 \mathrm{~A}, 3,11$ and 14 (Table 1). The agerelated distribution of the most prevalent serotypes is depicted in Fig. 1. The 7vPCV serotypes, as well as the crossprotective serotypes, invariably showed peak incidences at the age of 1-2 years, whereas the incidence of the majority of the non-vaccine serotypes peaked at an older age.

A total of 578 (96\%) of the pneumococci were available for genetic analysis by means of RFEL genotyping. We observed 337 genetically distinct genotypes, of which 153 genotypes were unique (i.e. found once only). The remaining 425 pneumococcal isolates (74\%) comprised 92 genetic clusters. Of the RFEL clusters observed in our collection, five showed close homology with RFEL profiles of the international PMEN clones. The PMEN genotype Spain ${ }^{9 \mathrm{~V}}-3$ was observed ten times, England ${ }^{14}-9$ four times, Tennessee ${ }^{23 \mathrm{~F}}-4$ two times, $\mathrm{CSR}^{14}-10$ once and Sweden ${ }^{15 \mathrm{~A}}-25$ once. In Fig. 2, all genetic clusters are represented in a genetic dendrogram, which includes the serotype distribution, age distribution, and number of isolates representing each cluster. In contrast to the age-related serotype distribution, the dendrogram suggests no additional correlation between age and genetic profile, except for cluster I, which showed a mean age of 11 years, compared with 6 years for the entire pneumococcal population.

In Table 2, we list the nine largest genetic clusters, each representing more than ten isolates. The largest cluster, cluster V, consisted of 45 strains of serotype 6B (Veenhoven et al., 2003), 6A (Butler et al., 1999) and 19F (Black et al., 2002), representing five genotypes. No homology was observed with any of the PMEN clones. The second and third largest clusters, cluster VIII (18 strains) and cluster I (17 strains), represented two and three genotypes, respectively, and harboured mainly serotype 3. Only one major cluster, cluster IX, representing serotypes 9V and 19F (13 strains), showed close homology (>95\%) with an international clone, which was Spain ${ }^{9 \mathrm{~V}}-3$. MLST analysis showed that cluster IX and Spain ${ }^{9 \mathrm{~V}}-3$ had five out of seven alleles in common. In contrast to the original PMEN clone, all Dutch isolates were fully susceptible to penicillin, tetracycline, erythromycin and cotrimoxazole. The remaining clusters, i.e. cluster II (13 strains), cluster III (10 strains), cluster IV (13 strains), cluster VI (10 strains) and cluster VII (12 strains), represented predominantly the serotypes 14,15 ,

Fig. 2. Dendrogram of the 92 genetic clusters observed by RFEL genotyping among the Dutch S. pneumoniae nasopharyngeal isolates. The figure shows serotypes (with number of strains per serotype in parentheses), bars representing the mean ages of children carrying the isolates, number of isolates per RFEL cluster, and cluster codes. NT, not typable. 
23F, 23F and 23F, respectively. Six of the nine major clusters consisted of $7 \mathrm{vPCV}$ serotypes, whereas only three clusters represented the non-vaccine serotypes 3 and 15 .

We characterized the 24 largest clusters by MLST (Fig. 3). This method confirmed the presence of an additional PMEN clone, namely England ${ }^{14}-9$. The remaining clusters showed sequence types (STs) differing from the international multidrug-resistant clones; however, most clusters matched STs present in the international database.

Susceptibility testing was performed on 587 pneumococcal isolates for the following antimicrobial drugs: penicillin, erythromycin, tetracycline, cotrimoxazole, chloramphenicol, cefotaxime, ciprofloxacin and vancomycin. In total, $18 \cdot 1 \%$ of the isolates showed resistance to one or more of the antimicrobial drugs investigated. Resistance to cotrimoxazole, erythromycin and tetracycline was found in $12 \cdot 9,5 \cdot 0$ and $5.6 \%$ of isolates, respectively. Resistance to vancomycin and ciprofloxacin was not observed. In $13.6 \%$ of the isolates, resistance to a single drug was observed. In $2.6 \%$ of the isolates, dual resistance was found, and multidrug resistance was found in $1.9 \%$ of isolates. High-level penicillin resistance was not observed; however, $2.7 \%$ of the pneumococcal isolates showed intermediate susceptibility to penicillin. In addition, the majority of these strains (11 out of 15 isolates) showed dual or multidrug resistance. Table 3 gives the number of strains, resistance level, and the mean ages of the

\begin{tabular}{|c|c|c|c|c|c|c|c|c|c|c|c|c|c|c|c|}
\hline 50 & 60 & 70 & 80 & 90 & $100 \%$ & Cluster & Serotype & $\mathrm{ST}$ & $\operatorname{aro} E$ & $g d h$ & $g k i$ & recP & $s p i$ & $x p t$ & $d d l$ \\
\hline & & & & & & II & 14 & 124 & 7 & 5 & 1 & 8 & 14 & 11 & 14 \\
\hline & & & & & & $\mathrm{X}$ & 14 & $9^{*}$ & 1 & 5 & 4 & 5 & 5 & 1 & 8 \\
\hline & & & & & & III & 15 & 199 & 8 & 13 & 14 & 4 & 17 & 4 & 14 \\
\hline & & & & & & III & 15 & 199 & 8 & 13 & 14 & 4 & 17 & 4 & 14 \\
\hline & & & & & & XII & 16 & 414 & 1 & 5 & 27 & 5 & 1 & 28 & 1 \\
\hline & & & & & & $\mathrm{XI}$ & 4 & 205 & 10 & 5 & 4 & 5 & 13 & 10 & 18 \\
\hline & & & & & & XIII & $18 \mathrm{C}$ & 113 & 7 & 2 & 1 & 1 & 10 & 1 & 21 \\
\hline & & & & & & IV & $23 \mathrm{~F}$ & 36 & 1 & 8 & 4 & 1 & 1 & 4 & 6 \\
\hline & & & & & & I & 8 & 447 & 29 & 33 & 19 & 1 & 36 & 22 & 31 \\
\hline & & & & & & I & 8 & 447 & 29 & 33 & 19 & 1 & 36 & 22 & 31 \\
\hline & & & & & & I & 3 & 447 & 29 & 33 & 19 & 1 & 36 & 22 & 31 \\
\hline & & & & & & XIV & 11 & 408 & 2 & 5 & 6 & 12 & 16 & 3 & 14 \\
\hline & & & & & & XIV & 11 & 62 & 2 & 5 & 29 & 12 & 16 & 3 & 14 \\
\hline & & & & & & $X V$ & $23 \mathrm{~A}$ & 42 & 1 & 8 & 9 & 9 & 6 & 4 & 6 \\
\hline & & & & & & XVI & $23 \mathrm{~A}$ & 1040 & 1 & 8 & 9 & 9 & 6 & 26 & 6 \\
\hline & & & & & & XVII & $6 \mathrm{~A}$ & 1141 & 2 & 13 & 9 & 6 & 6 & 19 & 14 \\
\hline & & & & & & V & $6 \mathrm{~B}$ & 176 & 7 & 13 & 8 & 6 & 10 & 6 & 14 \\
\hline & & & & & & V & $6 \mathrm{~A}$ & 1143 & 7 & 25 & 4 & 1 & 15 & 1 & 28 \\
\hline & & & & & & XVIII & $6 \mathrm{~B}$ & 176 & 7 & 13 & 8 & 6 & 10 & 6 & 14 \\
\hline & & & & & & XIX & $6 \mathrm{~B}$ & 176 & 7 & 13 & 8 & 6 & 10 & 6 & 14 \\
\hline & & & & & & V & $6 \mathrm{~B}$ & 176 & 7 & 13 & 8 & 6 & 10 & 6 & 14 \\
\hline & & & & & & $\mathrm{XX}$ & $19 \mathrm{~F}$ & 177 & 7 & 14 & 4 & 12 & 1 & 1 & 14 \\
\hline & & & & & & $X X$ & $19 \mathrm{~F}$ & 1045 & 7 & 14 & 4 & 12 & 1 & 14 & 14 \\
\hline & & & & & & XXI & $19 \mathrm{~F}$ & 236 & 15 & 16 & 19 & 15 & 6 & 20 & 26 \\
\hline & & & & & & XXI & $19 \mathrm{~F}$ & 236 & 15 & 16 & 19 & 15 & 6 & 20 & 26 \\
\hline & & & & & & VII & $23 \mathrm{~F}$ & 440 & 7 & 5 & 1 & 1 & 13 & 31 & 14 \\
\hline & & & & & & VII & 17 & 392 & 7 & 5 & 1 & 1 & 6 & 31 & 14 \\
\hline & & & & & & XXII & $23 \mathrm{~F}$ & 440 & 7 & 5 & 1 & 1 & 13 & 31 & 14 \\
\hline & & & & & & VI & $23 \mathrm{~F}$ & 440 & 7 & 5 & 1 & 1 & 13 & 31 & 14 \\
\hline & & & & & & XXIII & 38 & 1140 & 7 & 43 & 41 & 18 & 13 & 49 & 6 \\
\hline & & & & & & XXIII & 38 & 393 & 10 & 43 & 41 & 18 & 13 & 49 & 6 \\
\hline & & & & & & XXIII & 38 & 393 & 10 & 43 & 41 & 18 & 13 & 49 & 6 \\
\hline & & & & & & VIII & 3 & 180 & 7 & 15 & 2 & 10 & 6 & 1 & 22 \\
\hline & & & & & & $\mathrm{IX} \dagger$ & $9 \mathrm{~V}$ & 1142 & 29 & 11 & 10 & 1 & 6 & 8 & 14 \\
\hline & & & & & & XXIV & 4 & 449 & 8 & 37 & 9 & 29 & 2 & 47 & 5 \\
\hline
\end{tabular}

Fig. 3. Dendrogram of 35 representative pneumococcal strains belonging to the 24 largest clusters. The MLST profiles of these strains are depicted. ${ }^{*} 100 \%$ homology with England ${ }^{14}-9 ;$ †5 out of 7 alleles showed homology with Spain ${ }^{9 \mathrm{~V}}-3$. 
Table 3. Susceptibility profiles of the pneumococcal isolates

\begin{tabular}{|lcccc|}
\hline Antibiotic & $\begin{array}{c}\text { Resistant } \\
\text { strains }\end{array}$ & $\begin{array}{c}\text { Intermediate-resistant } \\
\text { strains }\end{array}$ & Total $^{\star}$ & $\begin{array}{c}\text { Mean age } \\
\text { (years) } \dagger\end{array}$ \\
\hline Penicillin & $0 \cdot 0 \%$ & $2 \cdot 7 \%$ & $2 \cdot 7 \%$ & $7 \cdot 1$ \\
Tetracycline & $3 \cdot 9 \%$ & $1 \cdot 7 \%$ & $5 \cdot 6 \%$ & $5 \cdot 9$ \\
Erythromycin & $4 \cdot 5 \%$ & $0 \cdot 6 \%$ & $5 \cdot 0 \%$ & $5 \cdot 1$ \\
Cotrimoxazole & $7 \cdot 5 \%$ & $5 \cdot 5 \%$ & $12 \cdot 9 \%$ & $5 \cdot 7$ \\
Chloramphenicol & $0 \cdot 2 \%$ & $0 \cdot 0 \%$ & $0 \cdot 2 \%$ & $18 \cdot 0$ \\
\hline
\end{tabular}

${ }^{*}$ Values are percentages of the total number of strains tested.

$\dagger$ Mean age of the children carrying the isolates.

children carrying these isolates. No significant difference was observed for the mean ages of the children carrying resistant isolates $(5 \cdot 4$ years $)$ versus children carrying susceptible isolates $(5 \cdot 9$ years $)$, or for the individual resistance profiles.

We also determined the contribution of 7vPCV serotypes to the total number of resistant strains. Sixty out of 104 resistant strains belonged to serotypes covered by the 7valent conjugate vaccine ( $58 \%$ ), and 74 out of 104 resistant isolates $(71 \%)$ were found to be vaccine serotype isolates when the cross-protective serotypes $6 \mathrm{~A}, 9 \mathrm{~N} / \mathrm{L}, 19 \mathrm{~A} / \mathrm{B}$ and $23 \mathrm{~A} / \mathrm{B}$ were included; in both cases, the contribution of $7 \mathrm{vPCV}$ serotypes to resistance was significantly higher compared with the contribution of $7 \mathrm{vPCV}$ serotypes to the total group of pneumococci. In case of dual resistance 10 out of $15(67 \%)$ displayed 7vPCV serotypes and 11 out of 15 isolates $(73 \%)$ when cross-protective serotypes were included. With respect to multidrug resistance, 6 out of 11 (55\%) strains represented 7vPCV serotypes, and 7 out of 11 (64\%) represented $7 \mathrm{vPCV}$ serotypes when cross-reactive serotypes were included; however, numbers were too small to show significant differences compared with the contribution of $7 \mathrm{vPCV}$ serotypes to the susceptible pneumococcal population.

\section{DISCUSSION}

We studied the molecular epidemiology of 578 pneumococcal isolates retrieved from healthy children ranging from 12 months to 19 years of age in Rotterdam, The Netherlands. Genetic clustering was observed in $74 \%$ of the strains, which comprised 92 distinct genetic clusters. These data indicate both a high genetic diversity among pneumococci, and horizontal spread within the community. Moreover, because the majority of the strains were fully susceptible to the most common antibiotics, these data suggest that horizontal spread is by definition not related to (multi)drug resistance, as stated previously. Since the prevalence of resistant pneumococci was very low $(18 \cdot 1 \%)$, we were unable to compare the tendency to spread within the community between resistant and fully susceptible strains within this population.
In our cohort, the largest genetic cluster comprised mainly serotype $6 \mathrm{~A}$ and $6 \mathrm{~B}$ isolates. These isolates were fully susceptible to penicillin, tetracycline, erythromycin and cotrimoxazole. In addition, comparison of the genotypes of this cluster showed no close homology with any of the known serotype $6 \mathrm{~B}$ clones from the PMEN database (McGee et al., 2001). Of the genotypes observed in our collection, only five showed close homology with five distinct PMEN clones (McGee et al., 2001). These data indicate that the international drug-resistant clones do not significantly contribute to colonization and spread of pneumococci among children in The Netherlands. The data confirm the observations of recent studies performed in The Netherlands among day-care-centre attendees, and children suffering from recurrent acute otitis media (Bogaert et al., 2001, 2005).

Recently, we observed an age-related pneumococcal serotype distribution within our study population (Bogaert et al., 2003). Pneumococcal 7vPCV serotypes showed an initial peak incidence of $30 \%$ at the age of 1 year, after which a decline was observed to an incidence of $2-3 \%$ after the age of 8 years. For non-vaccine serotypes, an initial increase in incidence was observed to $27 \%$ at the age of 4 years, followed by a decline, which stabilized after the age of 15 years at $4 \%$ (Bogaert et al., 2003). This was mainly caused by the predominance of a limited number of predominant non-vaccine serotypes after the age of 3 years, i.e. serotypes 3, 8, 10 and 11. Children under 2 years of age show the highest risk for pneumococcal infections, and since these children carry mainly $7 \mathrm{vPCV}$ serotype strains, a difference in virulence between $7 \mathrm{vPCV}$ and non-vaccine serotypes might exist. Therefore, we investigated the agerelated distribution of genotypes. In contrast to the predominant serotype 3 cluster I with a mean age of 11 years, no age-related genetic clustering was observed. This observation supports the analyses of Brueggemann and Sandgren who reported that pneumococcal serotype and host factors, such as age, might be more important than genetic background in the progression of colonization to disease (Crook \& Spratt, 1998; Sandgren et al., 2004).

When evaluating the nine largest clusters, each harbouring 10 or more isolates, we observed that six of these clusters 
represented the conjugate vaccine serotypes $6 \mathrm{~B}, 14$ and $23 \mathrm{~F}$, whereas the remaining three clusters consisted of the nonvaccine serotypes 3,8 and 15 . These data suggest that besides $7 \mathrm{vPCV}$ serotype pneumococci, non-vaccine pneumococcal serotypes are also able to spread at high frequency within the community. These findings are in accordance with several vaccination studies, in which replacement of $7 \mathrm{vPCV}$ serotypes with non-vaccine pneumococcal serotype carriage was found in the nasopharynx after vaccination with a pneumococcal conjugate vaccine (Dagan et al., 2002; Mbelle et al., 1999; Veenhoven et al., 2003). However, the question remains whether these non-vaccine serotype strains are as pathogenic as their 7vPCV-serotype counterparts. Several studies have shown that replacement of $7 \mathrm{vPCV}$ serotypes with non-vaccine serotype pneumococci can cause mucosal disease (Eskola et al., 2001; Veenhoven, 2003); with respect to invasive disease, replacement has not yet been observed. However, Brueggemann et al. (2003) have demonstrated epidemiological evidence for the high invasive capacity of certain non-vaccine serotypes.

In $18 \cdot 1 \%$ of the strains studied, susceptibility testing showed resistance to at least one of the most commonly used antimicrobial drugs. Resistance to a single drug was observed most often $(13.6 \%)$, and multidrug resistance was found in only $1.9 \%$ of the isolates. Most commonly, we observed resistance to cotrimoxazole $(12 \cdot 9 \%)$, which is a first-line antibiotic used commonly in children in The Netherlands. Finally, we found antibiotic resistance to be associated with $7 \mathrm{vPCV}$-serotype pneumococci, which is in line with previous studies (Bogaert et al., 2002; Dobay et al., 2003; Watanabe et al., 2003).

We have established that drug resistance, with respect to pneumococcal carriage and disease, is still of minor concern in The Netherlands; however, a strict policy with respect to antibiotic prescription is still required.

In conclusion, pneumococcal colonization isolates from healthy Dutch children represent a heterogeneous genetic population of mostly susceptible strains, which display a high tendency to spread horizontally, irrespective of the age of the colonized children.

\section{ACKNOWLEDGEMENTS}

This study was sponsored by the Sophia Foundation for Medical Research, The Netherlands (grant 268), and the Dutch Science Foundation (grant SGO-Inf. 005). No financial conflict of interest was reported for any of the authors.

\section{REFERENCES}

Black, S. B., Shinefield, H. R., Ling, S., Hansen, J., Fireman, B., Spring, D., Noyes, J., Lewis, E., Ray, P., Lee, J. \& Hackell, J. (2002). Effectiveness of heptavalent pneumococcal conjugate vaccine in children younger than five years of age for prevention of pneumonia. Pediatr Infect Dis J 21, 810-815.
Bogaert, D., Engelen, M. N., Timmers-Reker, A. J., Elzenaar, K. P., Peerbooms, P. G., Coutinho, R. A., de Groot, R. \& Hermans, P. W. (2001). Pneumococcal carriage in children in The Netherlands: a molecular epidemiological study. J Clin Microbiol 39, 3316-3320.

Bogaert, D., Ha, N. T., Sluijter, M., Lemmens, N., de Groot, R. \& Hermans, P. W. (2002). Molecular epidemiology of pneumococcal carriage among children with upper respiratory tract infections in Hanoi, Vietnam. J Clin Microbiol 40, 3903-3908.

Bogaert, D., van Belkum, A., Sluijter, M., Luijendijk, A., Rumke, H., de Groot, R., Verbrugh, H. A. \& Hermans, P. (2003). Competition between Streptococcus pneumoniae and Staphylococcus aureus during colonisation is serotype-dependent. Lancet 363, 1871-1872.

Bogaert, D., Veenhoven, R. H., Sluijter, M., Wannet, W. J., Rijkers, G. T., Mitchell, T. J., Clarke, S. C., Goessens, W. H., Schilder, A. G., Sanders, E. A., de Groot, R. \& Hermans, P. W. (2005). Molecular dynamics of pneumococcal colonization in response to pneumococcal conjugate vaccination in children with recurrent acute otitis media. J Clin Microbiol 43, 74-83.

Brueggemann, A. B., Griffiths, D. T., Meats, E., Peto, T., Crook, D. W. \& Spratt, B. G. (2003). Clonal relationships between invasive and carriage Streptococcus pneumoniae and serotype- and clone-specific differences in invasive disease potential. J Infect Dis 187, 1424-1432.

Butler, J. C., Shapiro, E. D. \& Carlone, G. M. (1999). Pneumococcal vaccines: history, current status, and future directions. Am J Med 107, 69S-76S.

Centers for Disease Control \& Prevention (1997). Surveillance for penicillin-nonsusceptible Streptococcus pneumoniae - New York City, 1995. JAMA (J Am Med Assoc) 277, 1585-1586.

Crook, D. W. \& Spratt, B. G. (1998). Multiple antibiotic resistance in Streptococcus pneumoniae. Br Med Bull 54, 595-610.

Dagan, R., Givon-Lavi, N., Zamir, O., Sikuler-Cohen, M., Guy, L., Janco, J., Yagupsky, P. \& Fraser, D. (2002). Reduction of nasopharyngeal carriage of Streptococcus pneumoniae after administration of a 9-valent pneumococcal conjugate vaccine to toddlers attending day care centers. J Infect Dis 185, 927-936.

Dobay, O., Rozgonyi, F., Hajdu, E., Nagy, E., Knausz, M. \& Amyes, S. G. (2003). Antibiotic susceptibility and serotypes of Streptococcus pneumoniae isolates from Hungary. J Antimicrob Chemother 51, 887-893.

Eskola, J., Kilpi, T., Palmu, A. \& 11 other authors (2001). Efficacy of a pneumococcal conjugate vaccine against acute otitis media. $N$ Engl J Med 344, 403-409.

Faden, H., Stanievich, J., Brodsky, L., Bernstein, J. \& Ogra, P. L. (1990). Changes in nasopharyngeal flora during otitis media of childhood. Pediatr Infect Dis J 9, 623-626.

Gray, B. M., Converse, G. M., 3rd \& Dillon, H. C., Jr (1980). Epidemiologic studies of Streptococcus pneumoniae in infants: acquisition, carriage, and infection during the first 24 months of life. J Infect Dis 142, 923-933.

Hermans, P. W., Sluijter, M., Hoogenboezem, T., Heersma, H., van Belkum, A. \& de Groot, R. (1995). Comparative study of five different DNA fingerprint techniques for molecular typing of Streptococcus pneumoniae strains. J Clin Microbiol 33, 1606-1612.

Hermans, P. W., Sluijter, M., Dejsirilert, S., Lemmens, N., Elzenaar, K., van Veen, A., Goessens, W. H. \& de Groot, R. (1997). Molecular epidemiology of drug-resistant pneumococci: toward an international approach. Microb Drug Resist 3, 243-251.

Hoge, C. W., Reichler, M. R., Dominguez, E. A. \& 7 other authors (1994). An epidemic of pneumococcal disease in an overcrowded, inadequately ventilated jail. $N$ Engl J Med 331, 643-648.

Jefferies, J., Clarke, S. C., Diggle, M. A., Smith, A., Dowson, C. \& Mitchell, T. (2003). Automated pneumococcal MLST using 
liquid-handling robotics and a capillary DNA sequencer. $\mathrm{Mol}$ Biotechnol 24, 303-308.

Klugman, K. P. (1996). Epidemiology, control and treatment of multiresistant pneumococci. Drugs 52, 42-46.

Kristinsson, K. G. (1995). Epidemiology of penicillin resistant pneumococci in Iceland. Microb Drug Resist 1, 121-125.

Leiberman, A., Dagan, R., Leibovitz, E., Yagupsky, P. \& Fliss, D. M. (1999). The bacteriology of the nasopharynx in childhood. Int J Pediatr Otorhinolaryngol 49, S151-153.

Lenette, E. H., Balows, A, Hauser, W. J., Jr \& Shadomy, H. (1985). Manual of Clinical Microbiology, 4th edn. Washington, DC: American Society for Microbiology.

Mandigers, C. M., Diepersloot, R. J., Dessens, M., Mol, S. J. \& van Klingeren, B. (1994). A hospital outbreak of penicillin-resistant pneumococci in The Netherlands. Eur Respir J 7, 1635-1639.

Mbelle, N., Huebner, R. E., Wasas, A. D., Kimura, A., Chang, I. \& Klugman, K. P. (1999). Immunogenicity and impact on nasopharyngeal carriage of a nonavalent pneumococcal conjugate vaccine. J Infect Dis 180, 1171-1176.

McGee, L., McDougal, L., Zhou, J., Spratt, B. G., Tenover, F. C., George, R., Hakenbeck, R., Hryniewicz, W., Lefevre, J. C., Tomasz, A. \& Klugman, K. P. (2001). Nomenclature of major antimicrobialresistant clones of Streptococcus pneumoniae defined by the pneumococcal molecular epidemiology network. J Clin Microbiol 39, 2565-2571.

Muñoz, R., Coffey, T. J., Daniels, M. \& 8 other authors (1991). Intercontinental spread of a multiresistant clone of serotype $23 \mathrm{~F}$ Streptococcus pneumoniae. J Infect Dis 164, 302-306.

National Committee for Clinical Laboratory Standards (2002). Performance Standards for Antimicrobial Susceptibility Testing: Twelfth Informational Supplement, M100-S12. Wayne, PA: National Committee for Clinical Laboratory Standards.

Overweg, K., Bogaert, D., Sluijter, M., Yother, J., Dankert, J., de Groot, R. \& Hermans, P. W. (2000). Genetic relatedness within serotypes of penicillin-susceptible Streptococcus pneumoniae isolates. J Clin Microbiol 38, 4548-4553.

Principi, N., Marchisio, P., Schito, G. C. \& Mannelli, S. (1999). Risk factors for carriage of respiratory pathogens in the nasopharynx of healthy children. Ascanius Project Collaborative Group. Pediatr Infect Dis J 18, 517-523.

Sandgren, A., Sjostrom, K., Olsson-Liljequist, B., Christensson, B., Samuelsson, A., Kronvall, G. \& Henriques Normark, B. (2004). Effect of clonal and serotype-specific properties on the invasive capacity of Streptococcus pneumoniae. J Infect Dis 189, 785-796.

Sluijter, M., Faden, H., de Groot, R., Lemmens, N., Goessens, W. H., van Belkum, A. \& Hermans, P. W. (1998). Molecular characterization of pneumococcal nasopharynx isolates collected from children during their first 2 years of life. J Clin Microbiol 36, 2248-2253.

Tomasz, A. (1997). Antibiotic resistance in Streptococcus pneumoniae. Clin Infect Dis 24, S85-S88.

van Steenbergen, T. J., Colloms, S. D., Hermans, P. W., de Graaff, J. \& Plasterk, R. H. (1995). Genomic DNA fingerprinting by restriction fragment end labeling. Proc Natl Acad Sci U S A 92, 5572-5576.

Veenhoven, R. (2003). Impact of combined pneumococcal conjugate and polysaccharide vaccination on nasopharyngeal carriage in children with recurrent acute otitis media. In Program and Abstracts of the Third International Symposium on Pneumococci and Pneumococcal Diseases, 2002. Washington, DC: American Society for Microbiology.

Veenhoven, R., Bogaert, D., Uiterwaal, C. \& 9 other authors (2003). Effect of pneumococcal vaccine followed by polysaccharide pneumococcal vaccine on recurrent acute otitis media. Lancet 361, 2189-2195.

Watanabe, H., Asoh, N., Hoshino, K. \& 10 other authors (2003). Antimicrobial susceptibility and serotype distribution of Streptococcus pneumoniae and molecular characterization of multidrugresistant serotype $19 \mathrm{~F}, 6 \mathrm{~B}$, and $23 \mathrm{~F}$ pneumococci in northern Thailand. J Clin Microbiol 41, 4178-4183. 